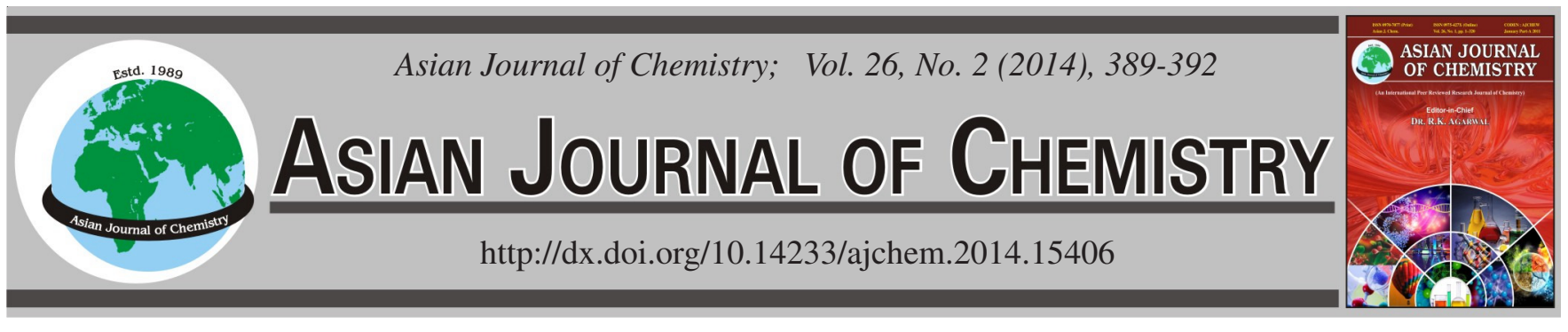

\title{
Utilization of Quaternized Rice Hull as Low-Cost Adsorbent for the Removal of Congo Red from Aqueous Solution
}

\author{
Siew-Teng Ong ${ }^{1,2, *}$, Li-Pei $\mathrm{Hew}^{3}$ and Yung-Tse $\mathrm{Hung}^{4}$
}

${ }^{1}$ Faculty of Science, Universiti Tunku Abdul Rahman, Jln Universiti, Bandar Barat, 31900 Kampar, Perak, Malaysia ${ }^{2}$ Centre for Biodiversity Research, Universiti Tunku Abdul Rahman, Jln Universiti, Bandar Barat, 31900 Kampar, Perak, Malaysia ${ }^{3}$ Faculty of Engineering and Science, Universiti Tunku Abdul Rahman, Jln Genting Kelang, Setapak, 53300 Kuala Lumpur, Malaysia ${ }^{4}$ Department of Civil and Environmental Engineering, Cleveland State University, Cleveland, Ohio, USA

*Corresponding author: Fax: +60 5 4661676; Tel: +60 5 4688888; E-mail: ongst_utar@yahoo.com; ongst@utar.edu.my

\begin{abstract}
In this study, the ability of quaternized rice hull to remove Congo Red from synthetic dye solution was investigated. The percentage uptake of Congo Red by quaternized rice hull was close to $50 \%$ and this corresponds to an enhancement of 6.6 folds as compared to natural rice hull. The effect of contact time, kinetic study, sorption isotherm, agitation rate and adsorbent dosage were studied under various experimental conditions. Batch studies revealed that adsorption was depended on contact time and concentration. For Congo Red with the concentration of $50 \mathrm{mg} / \mathrm{L}$, equilibrium was attained around $2 \mathrm{~h}$ whereas at higher concentration it requires a longer time. The adsorption of Congo Red onto quaternized rice hull followed pseudo-second order kinetic model with higher correlation coefficients as compared to pseudo-first order kinetic model. The maximum adsorption capacity of quaternized rice hull calculated using Langmuir model is $30.03 \mathrm{mg} / \mathrm{g}$.
\end{abstract}

Keywords: Quaternized rice hull, Congo Red, Sorption, Isotherm, Kinetics, Modelling.

\section{INTRODUCTION}

Dye is a common substance that has been widely used in many industries to add a colour to or change the colour of the substrate. The demand of dye has continuously increased, for example in textile, paper, plastics and cosmetics industries. As a result, the effluent discharged from these industries is highly coloured. This causes the difficulties in light penetration into water and affects the aquatic life. Apart from this, researchers have also determined that some dyes, dye precursors and their biotransformation products are toxic, mutagenic and carcinogenic in nature ${ }^{1}$. Hence, the removal of this contaminant from the aqueous environment is of utmost important. However, as dye is generally stable to light, oxidizing agent and resistant to aerobic digestion, the removal of dye can therefore be viewed as a challenging task.

Nowadays, many industries emphasized on environmental-friendly treatment methods. Therefore, it is important to discover or develop low cost and efficient methods for treating the industrial wastewater. In this context, adsorption is one of the noteworthy treatment processes and activated carbon can be considered as the most popular adsorbent which has been used with great success ${ }^{2}$. Because of its amphoteric properties, this enables activated carbon to adsorb both cationic and anionic species. However the cost of activated carbons can be considered quite high. Therefore, researches have been directed to make use of low cost materials such as agricultural byproducts or industrial waste which is low cost and at the same time have reasonable adsorption capacity to replace the expensive activated carbon. Some of the low-cost materials that have demonstrated its potential in removing dye include oil palm trunk fibre, hazelnut shells, wood sawdust, fly ash, papaya seed and sugarcane bagasse ${ }^{3-6}$.

Rice is the major staple food being consumed in many Asian countries. Rice hull is generated as a waste during the first stage of rice milling, when rough rice or paddy rice is husked (husk is separated from the rest of the grain). In general, $100 \mathrm{~kg}$ of paddy rice may generate $20 \mathrm{~kg}$ of hull. Exploring the possibility usage of this locally abundant waste material not only will reduce the environment burden but could also be beneficial to the economy. In this study, chemical modification has been imposed on this agriculture waste in order to enhance its adsorption capacity towards Congo Red.

\section{EXPERIMENTAL}

Adsorbent: Rice hull was obtained from a local rice mill in Kuala Terengganu, Malaysia. It was washed thoroughly with 
water to ensure the removal of dust and ash. Rice hull was then rinsed several times with distilled water and dried overnight in an oven at $50{ }^{\circ} \mathrm{C}$. The dried rice hull was then ground to pass through a $1 \mathrm{~mm}$ sieve and labeled as natural rice hull (NRH). $5 \mathrm{~g}$ of natural rice hull in $6.25 \mathrm{~mL}$ of $5 \mathrm{M} \mathrm{NaOH}$ solution was left at room temperature for $0.5 \mathrm{~h}$. At the end of this incubation period, 3-chloro-2-hydroxypropyl trimethylammonium chloride solution $\left(\mathrm{C}_{6} \mathrm{H}_{15} \mathrm{NOCl}_{2}, 65 \% \mathrm{w} / \mathrm{w}\right.$ in water) with $\mathrm{pH}$ adjusted to 5.3 was added to the mixture ${ }^{7}$. It was left in the oven at $60-70^{\circ} \mathrm{C}$ for $4 \mathrm{~h}$ with intermittent stirring. The reaction mixture was rinsed with distilled water and finally suspended in dilute $\mathrm{HCl}$ at $\mathrm{pH} 2$ for $0.5 \mathrm{~h}$. The resulting product was subsequently washed with distilled water until $\mathrm{pH}$ 5. After drying at $50^{\circ} \mathrm{C}$ overnight in the oven, it was termed quaternized rice hull $(\mathrm{QRH})$.

Adsorbate: The Congo Red dye powder purchased from Sigma-Aldrich was used without further purification. Fig. 1 shows that dye structure of Congo Red. Standard dye solution of $1000 \mathrm{mg} / \mathrm{L}$ was prepared as stock solution and subsequently diluted when necessary. The solution was kept in dark condition to prevent it from any light sources which may cause the degradation of dye solution.

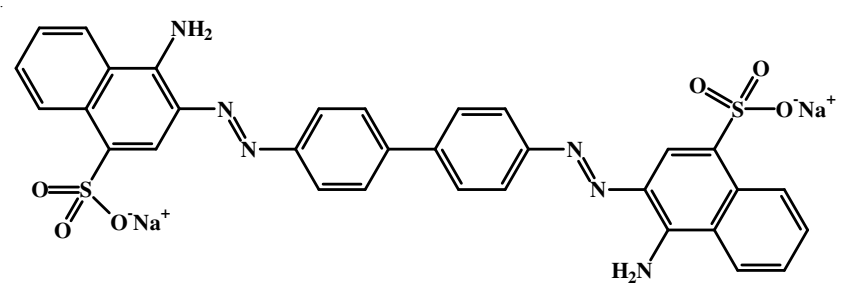

Fig. 1. Dye structure of Congo Red

Batch adsorption studies: All the batch adsorption experiments were performed in duplicate by agitating $0.10 \mathrm{~g}$ of quaternized rice hull in $20 \mathrm{~mL}$ of dye solution in a centrifuge tube and shaken at $150 \mathrm{rpm}$ on an orbital shaker at room temperature $\left(25 \pm 2{ }^{\circ} \mathrm{C}\right)$ unless otherwise stated. The results presented are the means value. Control without quaternized rice hull was simultaneously carried out to ascertain that the dye uptake was due to quaternized rice hull and not the wall of the centrifuge tube. At the end of the adsorption process, the mixtures were centrifuged at $3000 \mathrm{rpm}$ for phase separation. The Congo Red dye concentrations were analyzed using Perkin Elmer Lamda 35 double-beam UV/visible spectrophotometer with $1.0 \mathrm{~cm}$ light path cuvette (quartz cell) at the wavelength corresponding to maximum absorption, $\lambda_{\max }=498 \mathrm{~nm}$. Dilutions were carried out when the measurement exceeded the linearity of the calibration curve.

The percentage uptake of Congo Red was calculated by the following equation:

$$
\% \text { Uptake of Congo Red }=\left(\frac{\mathrm{C}_{\mathrm{o}}-\mathrm{C}_{\mathrm{e}}}{\mathrm{C}_{\mathrm{o}}}\right) \times 100
$$

where $\mathrm{C}_{\mathrm{o}}$ and $\mathrm{C}_{\mathrm{e}}(\mathrm{mg} / \mathrm{L})$ are the initial and equilibrium liquid phase concentration of Congo Red, respectively.

For the effect of initial dye concentration and contact time, both 50 and $100 \mathrm{mg} / \mathrm{L}$ Congo Red dye solutions were studied. The samples were withdrawn and analyzed for their dye concentrations at $5,10,15,30,60,120,180,240,300,360,420$ and $480 \mathrm{~min}$. Sorption isotherms were obtained by varying the Congo Red dye concentrations from 60 to $150 \mathrm{mg} / \mathrm{L}$. The effect of agitation rate was investigated by varying the agitation rate from 50 to $230 \mathrm{rpm}$. At predetermined intervals, the samples were withdrawn and analyzed for their dye concentrations. For the effect of adsorbent dosage, the study was conducted by varying the adsorbent dosage from 0.05 to $0.60 \mathrm{~g}$.

\section{RESULTS AND DISCUSSION}

Comparative uptake of Congo Red by natural rice hull and quaternized rice hull: The percentage uptake of Congo Red by quaternized rice hull was greater than natural rice hull. Under the controlled experimental condition, the percentage uptake for quaternized rice hull was $49.79 \%$ and this corresponds to an enhancement of 6.6 folds as compared to natural rice hull (Fig. 2). Rice hull is a cellulose-based biosorbent. It consists of both carboxyl and hydroxyl groups. During the chemical modification process, it is suggested that new functional group has been introduced on the rice hull. Quaternary ammonium cation might be attached to the cellulose of rice hull through the added N-(3-chloro-2-hydroxyl)trimethylammonium chloride and this can act as the positively charged site for the binding of negatively charged Congo Red anions. Therefore the percentage uptake of natural rice hull and MRH showed great difference.

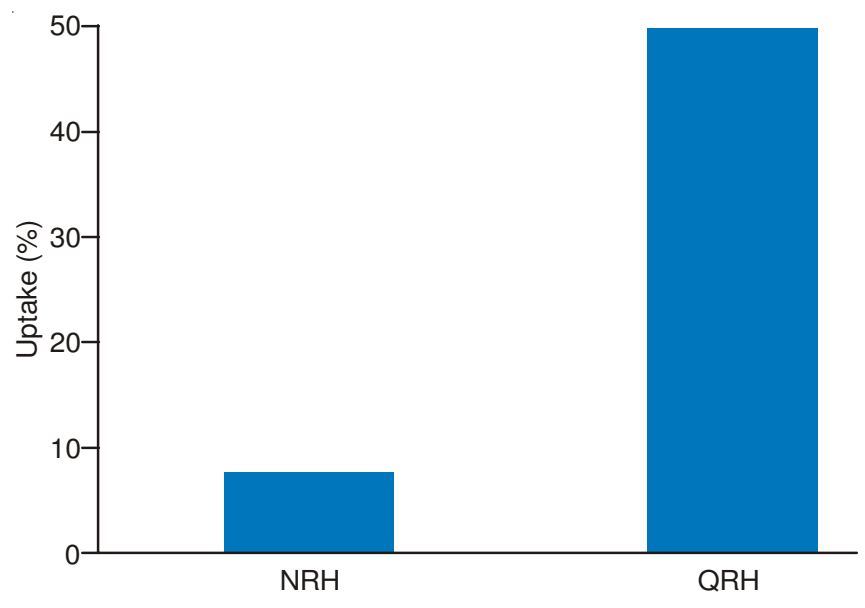

Fig. 2. Comparative adsorption of Congo Red by natural rice hull (NHR) and quaternized rice hull (QRH)

Effect of initial dye concentration and contact time: The percentage uptake of Congo Red by quaternized rice hull at different initial concentrations was shown in Fig. 3. In the first hour, the rate of uptake for both concentrations increased rapidly and equilibrium was attained at 120 and $300 \mathrm{~min}$ for 50 and $100 \mathrm{mg} / \mathrm{L}$, respectively. The result showed that at equilibrium, the percentage uptake of 50 and $100 \mathrm{mg} / \mathrm{L}$ were very close to each other which are about $99 \%$. From the same figure, the uptake of Congo Red by quaternized rice hull showed a smooth curve which indicated the possibility of monolayer coverage of Congo Red dye molecules on the surface of the adsorbent.

It is generally accepted that in a dynamic well stirred solidliquid system, the adsorption process can be separated into three stages ${ }^{8-10}$. At the beginning, Congo Red molecules 


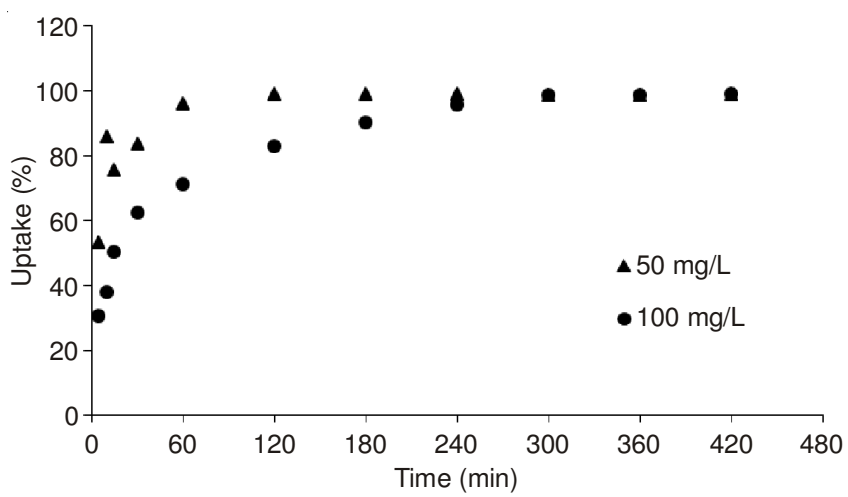

Fig. 3. Effect of initial dye concentrations and contact time on the uptake of Congo Red by quaternized rice hull

encountered the boundary layer first. After that, it will diffuse from the boundary layer film onto adsorbent surface. The second stage involves the diffusion into the porous structure of the adsorbent which requires a longer time before it reaches equilibrium. Finally, the last stage is the adsorption of Congo Red on the active sites on the internal surface of the pores.

Kinetics studies: In order to investigate the process of adsorption of Congo Red onto quaternized rice hull, two kinetics models were employed, namely pseudo-first and pseudo- second order kinetics models ${ }^{11,12}$. The equations for both models are shown as below:

$$
\begin{gathered}
\log \left(\mathrm{q}_{\mathrm{e}}-\mathrm{q}_{\mathrm{t}}\right)=\log \left(\mathrm{q}_{\mathrm{e}}\right)-\frac{\mathrm{k}_{1} \mathrm{t}}{2.303} \text { (pseudo- first order)(2) } \\
\frac{\mathrm{t}}{\mathrm{q}_{\mathrm{t}}}=\frac{1}{\mathrm{~h}}+\frac{\mathrm{t}}{\mathrm{q}_{\mathrm{e}}} \text { (pseudo- second order) }
\end{gathered}
$$

where $\mathrm{q}_{\mathrm{e}}=$ the amount of dyes adsorbed at equilibrium $(\mathrm{mg} / \mathrm{g})$, $\mathrm{q}_{\mathrm{t}}=$ the amount of dyes adsorbed at time $\mathrm{t}(\mathrm{mg} / \mathrm{g}), \mathrm{k}_{\mathrm{l}}=$ the rate constant of pseudo-first order sorption $(1 / \mathrm{min}), \mathrm{h}\left(\mathrm{k}_{2} \mathrm{q}_{\mathrm{e}}{ }^{2}\right)=$ the initial sorption rate $(\mathrm{mg} / \mathrm{g} \min )$ and $\mathrm{k}_{2}=$ the rate constant of pseudo- second order kinetics ( $\mathrm{g} / \mathrm{mg} \mathrm{min}$ ).

In this study, the correlation coefficients for the first order kinetic model obtained at both concentrations are in general lower than those of the second order model (Table-1). Besides, it was found that the pseudo-first order equation did not fit well for the whole range of concentrations studied and the equilibrium sorption capacities calculated based on this kinetic model gave unreasonable values compared to those determined experimentally (Table-1). This implies that the system under study is more appropriately described by the pseudo-second order and more than one parameter could be involved in the sorption process.

Besides, the theoretical sorption curves of Congo Red by quaternized rice hull were also plotted together with the experimental results for comparison purpose (Fig. 4). It was observed that the theoretical second-order model curves agreed

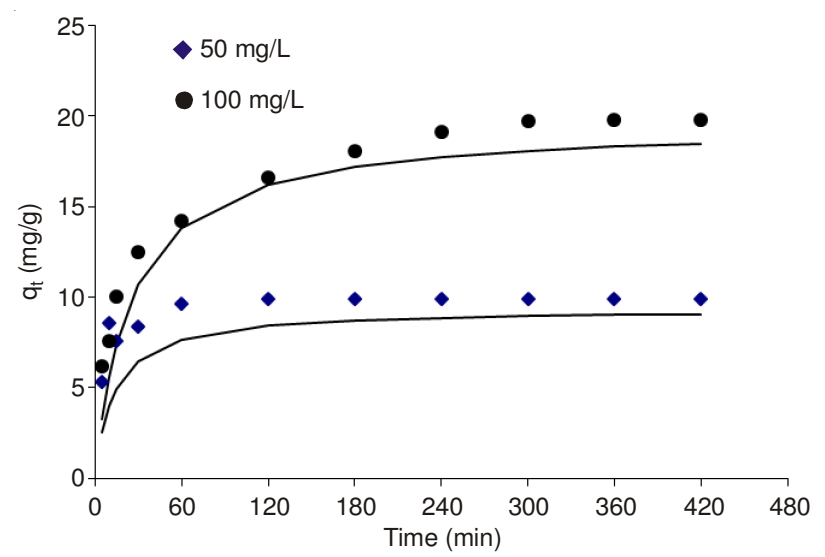

Fig. 4. Typical plots of comparison between the measured and pseudosecond order modelled time profiles for Congo Red sorption by quaternized rice hull

well with the experimental curves for the dye system under studied for the whole range of time. This agreed well with some of the previously reported work involving agricultural waste materials ${ }^{13,14}$.

Effect of agitation rate: Agitation is a classic parameter in sorption phenomenon. The identification of the rate-determining steps in sorption is important as it provides useful information on the rate parameters for design purpose. If mass transfer of dye molecules were an important factor in controlling the rate, then the rate of agitation would have an effect on the uptake. The experimental results obtained from a series of contact time studies for the sorption of Congo Red onto quaternized rice hull in which the degree of agitation was varied from 50 to $230 \mathrm{rpm}$ are presented in Fig. 5. At $420 \mathrm{~min}$, the percentage uptake of Congo Red at the agitation rate of 230, 150 and $50 \mathrm{rpm}$ was $98.99,97.37$ and $95.06 \%$, respectively. It thus appeared that the uptake of Congo Red by quaternized rice hull is agitation dependent whereby the uptake increased with increasing agitation rate. This is most probably due to the decreased in the film resistance to mass transfer surrounding the sorbent particles in a highly agitated system.

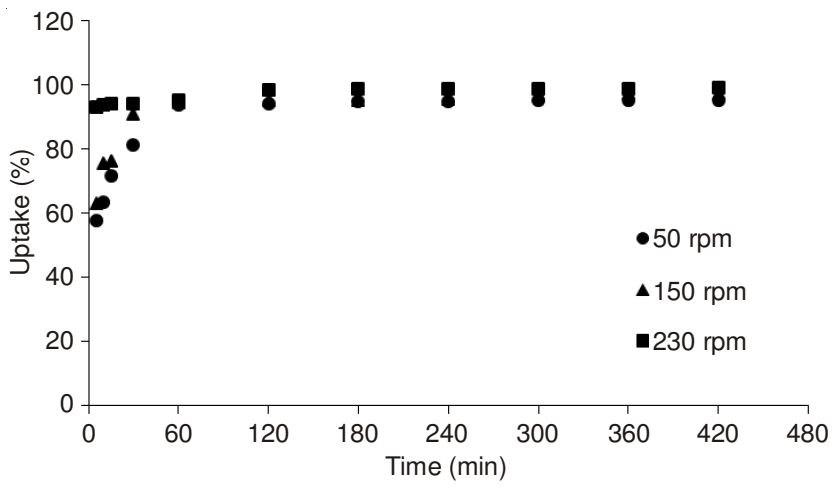

Fig. 5. Effect of agitation rate on the uptake of Congo Red by quaternized rice hull

TABLE-1

PSEUDO-FIRST AND PSEUDO-SECOND ORDER KINETIC MODELS PARAMETERS FOR ADSORPTION OF CONGO RED ONTO QUATERNIZED RICE HULL AT DIFFERENT INITIAL CONCENTRATIONS

\begin{tabular}{ccccc|ccc}
\hline $\mathrm{C}_{\mathrm{o}}$ & $\mathrm{q}_{\mathrm{e}, \exp }$ & \multicolumn{2}{c}{ Pseudo-first order kinetic model } & \multicolumn{3}{c}{ Pseudo-second order kinetic model } \\
\cline { 3 - 8 }$(\mathrm{mg} / \mathrm{L})$ & $(\mathrm{mg} / \mathrm{g})$ & $\mathrm{q}_{\mathrm{e}, \mathrm{cal}}\left(\mathrm{mg} \mathrm{g}^{-1}\right)$ & $\mathrm{k}_{1}\left(\mathrm{~min}^{-1}\right)$ & $\mathrm{R}^{2}$ & $\mathrm{q}_{\mathrm{e}, \text { cal }}\left(\mathrm{mg} \mathrm{g}^{1}\right)$ & $\mathrm{k}_{2}\left(\mathrm{~g} \mathrm{mg}^{-1} \mathrm{~min}^{-1}\right)$ & $\mathrm{h}\left(\mathrm{mg} \mathrm{mg}^{-1} \mathrm{~min}^{-1}\right)$ \\
\hline 50 & 9.898 & 3.981 & $1.04 \times 10^{-2}$ & 0.269 & 9.363 & $1.47 \times 10^{-2}$ & $\mathrm{R}^{2}$ \\
100 & 19.818 & 8.151 & $4.60 \times 10^{-3}$ & 0.391 & 19.570 & $2.80 \times 10^{-3}$ & 1.287 \\
\hline
\end{tabular}


Effect of adsorbent dosage: Table-2 showed the effect of adsorbent dosage on the percentage uptake of Congo Red by quaternized rice hull. As the adsorbent dosage increased from 0.05 to $0.60 \mathrm{~g}$, the percentage uptake of dye increased from 90.08 to $99.79 \%$. This is due to the increase of active sites for adsorption of dye molecules with increasing adsorbent dosage. The sorption equilibria of Congo Red were reached at $0.50 \mathrm{~g}$ and the uptake of Congo Red was kept almost invariable above this dosage. Similar observations have been reported previously in the adsorption involving basic dyes by sugarcane bagasse ${ }^{6}$. It is postulated that the saturation occurred because of the shortage of dye in the solution and also the accumulation of dye molecules on the surface of the adsorbent. This situation hinders the rest of the dye molecules from diffusing into the adsorbent. As such $0.50 \mathrm{~g}$ appeared to be the optimum adsorbent dosage for this study.

\begin{tabular}{|cc|cc}
\multicolumn{5}{c}{ TABLE-2 } \\
\multicolumn{4}{c}{ EFFECT OF ADSORBENT DOSAGE ON THE UPTAKE } \\
OF CONGO RED BY QUATERNIZED RICE HULL \\
\hline Dosage $(\mathrm{g})$ & Uptake $(\%)$ & Dosage $(\mathrm{g})$ & Uptake $(\%)$ \\
\hline 0.05 & 90.08 & 0.30 & 97.19 \\
0.10 & 90.60 & 0.50 & 99.15 \\
0.15 & 91.48 & 0.55 & 99.55 \\
0.20 & 92.65 & 0.60 & 99.79 \\
0.25 & 94.70 & - & - \\
\hline
\end{tabular}

\section{Conclusion}

The present study shows that quaternization of rice hull resulted in the formation of a sorbent (quaternized rice hull) that could be used successfully to remove Congo Red from aqueous solution. The 6.5 folds enhancement in the Congo
Red uptake by quaternized rice hull could be due to the introduction of new functional groups on the surface of the sorbent. Adsorption kinetics of quaternized rice hull followed pseudosecond-order with $\mathrm{R}^{2}$ close to unity. Besides, it was observed that the percentage uptake of dye increased with increasing contact time and agitation rate.

\section{ACKNOWLEDGEMENTS}

The financial support by the International Foundation for Science, Stockholm, Sweden and the research facilities by Universiti Tunku Abdul Rahman are acknowledged.

\section{REFERENCES}

1. W.H. Cheung, Y.S. Szeto and G. McKay, Bioresour. Technol., 100, 1143 (2008).

2. P.K. Malik, Dyes Pigments, 56, 239 (2003).

3. B.H. Hameed and M.I. El-Khaiary, J. Hazard. Mater., 154, 237 (2008).

4. F. Ferrero, J. Hazard. Mater., 142, 144 (2007).

5. S.T. Ong, S.P. Yip, P.S. Keng, S.L. Lee and Y.T. Hung, Afr. J. Agric. Res., 7, 810 (2012).

6. S.T. Ong, E.C. Khoo, S.L. Hii and S.T. Ha, Desalination Water Treat. J., 20, 86 (2010).

7. S.T. Ong, P.S. Keng and C.K. Lee, Am. J. Appl. Sci., 7, 447 (2010).

8. A. Findon, G. McKay and H.S. Blair, J. Environ. Health, 28, 173 (1993).

9. I. Saucedo, E. Guibal, C. Roulph and P. Le Cloirec, Environ. Technol., 13, 1101 (1992).

10. B. Koumanova, P. Peeva and S. Allen, J. Chem. Technol. Biotechnol., 78, 582 (2003).

11. S. Lagergren and B.K. Svenska, Veternskapsakad Handlingar, 24, 1 (1898).

12. Y.S. Ho and G. McKay, Process Biochem, 34, 451 (1999).

13. S.T. Ong, S.Y. Tan, E.C. Khoo, S.L. Lee and S.T. Ha, Desalin. Water Treatment J., 45, 161 (2012).

14. S.T. Ong, P.S. Keng, S.T. Ooi, Y.T. Hung and S.L. Lee, Asian. J. Chem., 24, 398 (2012). 